Title: Navigating iScapes: Australian Youth constructing identities and social relations in a network society

Short form of title/running head: Navigating iScapes

\title{
Authors:
}

Kerry Mallan

Queensland University of Technology, Australia

Barbara Ashford

Queensland University of Technology, Australia

Parlo Singh

Griffith University, Australia 


\title{
Navigating iScapes:
}

\section{Australian Youth constructing identities and social relations in a network society}

\begin{abstract}
This paper extends Appadurai's notion of "scapes" to delineate what we see as "iScapes". We contend that iScapes captures the way online technologies shape interactions that invariably filter into offline contexts, giving shape and meaning to human actions and motivations. By drawing on research on high school students' online activities we examine the flow of iScapes they inhabit in the process of constructing identities and forming social relations.
\end{abstract}

Key Words: identities, scapes, network societies, youth, friends, iScapes

\section{Introduction}

Conventional understandings of identity and social relations are undergoing change in the light of new digital technologies' capacity to render space fluid and flexible. The popularity of social networking sites such as MySpace and Facebook has demonstrated how these new spaces support social contact and enable individuals to develop a 'profile' that can extend beyond the geographical limits of their offline worlds. For boyd (2007), the act of creating and maintaining profiles on social networking sites serves as "an initiation rite" into these spaces, which have become an important part of youth culture in many parts of the world. It is this convergence between technology and the individual that gives rise to the fluidity and multiplicity of identity and social relations for young people growing up in a networked society. However, the dynamics 
of these spaces are constantly changing due to the rapid evolution of new technologies. Consequently, understanding and accounting for this fluidity of identity and social relations requires new ways of conceiving the relationships between technology and youth, and the various overlapping spaces they interact with on an everyday basis. Furthermore, these 'localised' spaces need to be understood within a larger framework of global networks to enable a more complex understanding of the local - global impact on youth identity.

One of the problems in studying the activity of contemporary youth living in networked places is finding a way in which to trace the flow of objects, texts and bodies that travel across online and offline spaces, particularly when these spaces are treated as separate and distinct. In revisiting traditional ethnographic constructs of space and identity, Leander and McKim (2003) point out the way in which the moving practices of adolescents online have brought about a challenge to research paradigms. The authors argue that the destabilization of place as a situated and bounded entity necessitates the development of suitable interpretative methodologies for studying the everyday online practices of adolescents. Leander and McKim suggest a fresh approach to the concept of space/time that borrows from the relational theory developed by other theorists (Lefebvre 1991; Harvey 1990; Soja 1996). They endorse the view of these theorists that space be conceptualized as being socially constructed rather than as static or absolute. Thus they draw on a relational theory in which space is envisaged as contingent and contained in social and biological processes. Leander and McKim see this social constitution of space as a subject for analysis rather than an assumed starting point of research (2003: 224). 
Our research extends the relational approach to space - time reported by Leander and McKim, by introducing Appadurai's notion of 'scapes' to assist in understanding the complex play between fluidity and fixity as Australian youth build and experience online/offline relationships and identities. We do not characterize online and offline as absolute and differing spatial zones of youth experience, but argue that both zones interpenetrate. Our discussion considers how young people's online and offline everyday practices are "co-articulated” (Leander and McKim 2003: 212). Rather than see young people's participation in online worlds as separate from their offline interactions, we contend that young people's identities and friendships are inflected by the techno-social situatedness of their everyday lives. Thus, this article takes Appadurai's notion of scapes, and considers how this construct can be re-described in a way that accounts for the fluidity and multiplicity of identity and social relations for young people growing up in a networked society. To assist us with this re-description we have created a neologism "iScape" as a conceptual and linguistic tool for illustrating how local experience is embedded in more "glocal", technological scapes (Robertson 1995). Given this context, we ask: "How do interactions across iScapes impact upon the identity work carried out by today's youth?" and "How do young people negotiate the diverse, physically located, social situations that arise from these interactions?'.

To support our discussion, we draw on our research on how high schools students from Queensland, Australia negotiate sociality and identity formation as part of their everyday lives. Our interest lies in understanding the complexities that shape these young people's networked lives. The students' comments about their experiences reflect the various iScapes flows that move through home, school, and in the community. This paper addresses the importance of 
understanding the network of complexities that young people encounter in their everyday lives, and how these complexities infuse youth's constructions of their own shifting identities and social relationships.

\section{Theorising iScapes and relational space-time of identity construction}

Our coining of the term "iScapes" is an attempt to capture the ubiquity of technology as it weaves into the fabric of everyday life, especially in relation to how individuals use the Internet to establish interconnectivity and construct identities. As language acts as a marker of changing times, it also reflects back society as it changes. The advent of digital technologies has ushered in new words or neologisms that can be useful tools for understanding how culture is evolving. The Internet and computer technology have spawned a large and specialized lexicon. For example, the prefix "e" continues to be productive in generating new terms such as email, ebooks, epolitics, erecruit, to name just a few. Another prefix that is gaining increasing marketing and general usage is " $\mathrm{i}$ ". Like the "e" prefix, "i" can be attached to numerous words; but whereas "e" is shorthand for "electronic", "i" carries different associations - Internet, information, identity, individual. Since the iMac was first named, "i" has become not only a prefix but symbolic of many technological products such as iPod and iPhone. As a product name, we see it as also having association with individualism and the kind of identity that is packaged as part of the marketing and consumption of these and other digital goods. In this sense, the current ' $i$ ' generation of consumers and products serves as a useful indicator of how (Western) individualism underlies modern technologies and competitive market economies. Several writers have commented on the shift toward more individualistic behaviours and attitudes among the current generation of young people living in the Western world (Buckingham 2008). This has given rise to epithets such as 
the "Look at me generation" or the "Generation Me" (Twenge 2006).

In providing a range of theoretical and conceptual strategies or tools we aim to cut through the Westernising/globalising gloss apparent in the above statements about youth, by considering less totalizing concepts of youth. We also want to investigate some of the effects of technology that impact on family, school, and individual life. By working within the broader conceptual field of scapes and drawing on relational theories of space-time, we build a theoretical framework for explaining how young people negotiate the contradictory pressures towards homogenisation and heterogeneity. In other words, how individuals attempt to be like everyone else or fit in, while at the same time preserving their own sense of individual identity.

In writing about the debates concerning the nature of heterogenizing or homogenizing effects of global cultural flows, that is, how the global reach of standardization is both embraced and resisted, Appadurai (1990/1996) suggests a terminological shift. He employs the metaphor "scapes" to explain the complex dialogic construction of social environments through which information, technology, people, money and ideas move. The notion of scapes is used as the basis for a fine-grained and situated analysis of conditions in the globally-connected world and allows for the fluidity of global cultural flows where physical borders no longer necessarily sustain locality. In this way Appadurai is able to suggest a way to frame and analyse the dynamics of the complex relationships between local and global forces and environments. Scapes are "deeply perspectival constructs, inflected very much by the historical, linguistic and political situatedness of different sorts of actors" (Appadurai 1990: 296). Appadurai identifies five scapes to capture the global flows of people (ethnoscape), technology (technoscape), capital (financescape), images 
(mediascape), and ideologies (ideoscape). For this article, the concept of technoscape, mediascape and ideoscape offers the most useful constructs. By technoscape, Appadurai refers to the global configuration of technology and the fact that technology, particularly electronic or etechnology facilitates the movement of information, images and sounds at high speeds across what were once impervious boundaries. The concept of ethnoscape is also useful in that it refers to the movement of people as travelers, migrants, refugees, students, workers and so forth. A number of the youth interviewed in our study spoke of changing schools, moving inter-state, past, current and future plans for travel. At the same time, they spoke of the ways in which etechnologies were used to maintain social relations with friends even though they may not be located in the same geographic place. Crucially, Appadurai argues that the global relationship between the scapes is deeply disjunctive and unpredictable, since each is subject to its own constraints and incentives; at the same time, each acts as a constraint and a parameter for the movements in the other.. Appadurai posits that these five scapes offer a framework for examining the "new global cultural economy a complex, overlapping, disjunctive order that cannot any longer be understood in terms of existing center-periphery models" (Appadurai 1996: 32). At the same time, however, mass mediation and mass movement of people are two major interconnected forces that work on the imagination and are a 'constitutive feature of modern subjectivity' (Appadurai, 1996: 3).

The contribution of scapes is that they provide an alternative spatial conceptualizing of the present. Whereas landscapes may appear fixed and change seems to occur over an extended period of time, current technologies are rendering iScapes as unfixed, fluid, amorphous, and of various sizes. While Appadurai sees scapes as the "building blocks" of contemporary imagined worlds, we conceive of iScapes, not as building blocks, but as 
interconnecting networks through which identity work is undertaken. We agree with Appaduari's point regarding the value of imagination, especially its association with individual subjectivity and with agency. However, agency is a variable condition for many young people who are often restricted or denied full agency in making chooses about what they would like to do and the company they would like to keep. In this way, we see the conceptual flexibility of iScapes encompassing both the imagination and the individual, particularly in how individuals imagine themselves as they navigate and experience these iScapes. In relation to his global scapes, Appaduari suggests that "the individual actor is the last locus of this perspectival set of landscapes, for these landscapes are eventually navigated by agents who both experience and constitute larger formations, in part from their own sense of what these landscapes offer" (1996: 33). Our research considers how adolescents similarly are part of a larger formation, which impacts on their sense of identity.

While Appaduari's argument is concerned with the global political economy and the need for consideration of the shifting relationship between human movement, technological flow, and financial transfers, our interest is more localized. Rather than utilize technoscape as it is conceptualized by Appaduari, we see 'iScapes' as a way of capturing the different zones that young people engage with as they negotiate the constraints and incentives of a technologicallymediated existence. Just as Appadurai considers both the relationships and disjunctures between his five scapes, we too conceive of young people's movement across iScapes as inevitably connected, but also separated. Thus the concept of iScape refers to the construction of individual subjectivity or identity within and between the scapes of e-technologies and land-scapes. The ' $\mathrm{i}$ ' 
refers to both to the individualism of the Western self, as well as the digitial construction of 'me' in and through the e-spaces of technoscapes - myspace, facebook, twitter and so forth.

Digital environments do not replace other physical-geographical spaces (for example, shopping malls, schools, sporting venues, cinema), but extend and integrate these social spaces across online and offline worlds. This point is further supported by Lewis and Fabos (2005: 275) who suggest, "online communication appears not to have displaced face-to-face interactions and may well play a role in sustaining them". The distinction between online and offline worlds is often blurred and people continue to occupy both virtual/e-scapes and land-scapes simultaneously. However, the apparently effortless merging of the physical and digital environments obscures the ways in which these hybrid environments create new conditions under which identity is prescribed, performed, and perceived, and therefore warrants attention. For many parents and teachers, young people's participation in online communities through social networking sites, online games, or blogs is a source of concern about the "perils" of cyberculture. When young people engage with the global reach of a distributed network, they embody new technological modes of being which are often visible. It is this visibility which gives rise to fears of young people being vulnerable and susceptible. However, there is another side to this perception, one which considers the many advantages and opportunities that online worlds offer for communicating and coordinating social lives, for creating an outlet for self-expression, and for accessing computer-supported community networks (Jenkins, 2006; Livingstone, 2009).

In Australia, as in many developed countries, there is a flourishing cyberculture and network society supported by government and private sector sponsored computing and telecommunication infrastructures, applications and devices. As we noted previously, one of the problems for the 
work of studying the activity of contemporary youth living in networked places is finding a way in which to trace the flow of objects, texts and bodies that travel across online and offline spaces, particularly when these spaces are treated as separate and distinct. Another is understanding how far we can conceive of the local (or national) as different from the global (or international). In other words, in speaking of Australian youth how different are they from youth living in other Western societies? Also, how does difference characterize Australian youth? The problem of speaking of a nation is that we imagine the collective as sharing similar experiences. However, the spaces for being different or experiencing "otherness" is not a figment of the imagination but possible through the social spaces that already exist. Nevertheless, globalization and capitalism have constructed a distinctive social-political landscape, whereby Australia is connected to and benefits from the five scapes, with a technoscape producing a space of transport and communications, infrastructures and organizations that support capital production and technological innovation.

Activity in the technoscape transcends national boundaries and has often been conceived through media representations, everyday practice and academic research as separate to the real offline world (Dodge \& Kitchin 2001). As noted in the introduction, the concept of space is now generally understood as social and productive, and interpenetrating physical and virtual realities. In this way, space is also a production, shaped by various social processes and human interventions, and "a force that, in turn, influences, directs, and delimits possibilities of action" (Wegner 2002: 11). For Leander and McKim (2003), emerging social spaces, such as cyberspace, are not received by subjects as some hitherto uncharted world but are experienced through interrelated practices that are complexly interpenetrated with familiar socially constituted spacetime. A relational approach to space opens out the discussion of online and offline practices in 
three key ways. It allows us to examine the interpenetrations of youth's experiences online and offline while also investigating how multiple space-times can be involved in a given social situation at once. It also enables us to see how individuals can intervene in the dynamic and openended process of space. There is a further point that David Harvey (1990: 218-21) makes that adds value to our understanding of space. By reconceiving Lefebvre's notion of "lived space", Harvey substitutes the idea of "imagined" space. This point correlates with Appadurai's regarding the value of the imagination. In the context of cyberspace, the imagined communities that develop construct membership, rules, and social practices in often prescribed ways. Yet, ironically the openness of technologically-mediated spaces encourage a continual process of change to these conditions. We however see value of both the lived and the imagined in explaining how youth both experience and imagine themselves in online worlds and how they translate into their offline activities.

As explained earlier, our use of the term iScapes offers a new perspective to current understanding of how online technologies shape interactions and identity performance that invariably filter into offline contexts. Conceptually, iScapes encompasses the pervasive and mediating presence of technology in our lives (mobile phones, computers, MP3 players, iPods). By reconceptualising the fluid activity with and across technology, we resolve the dilemma that arises from the dichotomous perception between online/offline. For Castells, to continue distinguishing between the online and offline "make(s) an understanding of the new patterns of social interaction difficult" (2001:117). Such a distinction also fails to take account of new patterns of social interaction and identity formation that are assisted by technology. As Slater (2002) and others argue, networked enabled relationships that transcend the restrictions of time and space have produced new forms of sociality and identity formation that cross the perceived 
online/offline divide. These new cyber-influenced identities and social relationships are possible largely because the spatio-temporal aspects of human experience have been transformed.

Identity formation is often theorized in terms of the self in relation to others (Valentine \& Holloway 2002). Such explorations of identity in relation to the social circumstances that construct the existence of the self have been one of the key concerns of modernity. While we agree that the self-other dialectic plays a significant part in identity processes, we contend that identity formation is not a simple transaction process between self and others. Our view is that identity is in a constant process of formation and change, which involves complex relations between self and others across spatio-temporal scapes. These scapes are subject themselves to change through the global flows and movements that Appadurai identifies. For many young people living in countries like Australia this process of change occurs within the global and local network that is both formed by, and expresses, structures of power. The global is therefore a significant force that impacts on the way young people see themselves within their local reality.

Buckingham (2008:1) acknowledges the ambiguity of the term "identity". He suggests that one reason for this is the inherent contradiction of two fundamental aspects of the concept. In any discussion of identity, tension exists between a sense of a unifying collective on the one hand and distinguishable personal difference on the other. Both meanings are implicated in the perception of what constitutes identity. The play between shared collective identity and unique singular distinction confounds an easy understanding of identity formation and this complexity is further complicated when the relational world in which adolescents move shifts between so-called real and virtua/ life experiences. Our position is that both aspects of identity (as collective and 
individual) are formulated within a world in which the subject is a participant. Therefore, all experiences that constitute identity negotiation are relational.

In the following sections, we utilize the concept of iScapes and the theories we have outlined to our discussion of our research work with youth. We argue that identity formation is an ongoing and negotiated process that takes place in diverse interpenetrated social contexts that transcend the here and now of physical space. By utilizing the concept of iScapes we interpret how the students in this study see their lives as situated within, affected by, and contributing to the global flows of people, ideas, images, and sounds.

\section{The Study}

\section{Participants}

The students who participated in this study were drawn equally from two urban and two regional locations in Queensland (Australia). The students came from diverse social, cultural and economic situations, despite the fact that the four participating schools were privately funded. In Australia, the private education system includes fee-paying schools from the high end of the social-economic scale which demand expensive school fees, to religious-affiliated schools that may require modest fees. However, both offer scholarships that support enrolments from students from lower socio-economic backgrounds.

The students were aged between 13 and 16 years, coming from a range of ethnic backgrounds and cultural and religious identifications. A small number of students came from families who had moved several times due to changing employment as well as those who had migrated from 
overseas to live in Australia. All students came from homes that had at least one computer and Internet access. However, many of the students from one of the regional schools were unable to access Broadband, which impacted on the time they could spend on the computer. In the two urban schools and one of the regional schools, most students had a personal mobile phone which become a conduit for maintaining social relations and connectivity. Many students across all the schools were social network site (SNS) participants. MySpace was by far the most frequently mentioned SNS across all four schools. Students either had a MySpace profile or had had one at some time in the recent past. Less popular SNS mentioned included Bebo, Hi-5, Piczo and Flixster.

\section{Research Design}

This qualitative research involved a series of semi-structured focus groups conducted with 170 students in their schools between 2006 and 2008. The intention of this research was to gain specific information on how students interact with digital technologies, not to carry out a comparative analysis across the focus groups. The restrictions that were placed on our access to the students in the schools meant that we were unable to do follow up interviews with many of the students. Furthermore, our access to information about individual circumstances was also restricted by the terms of the ethical agreement with the schools. Two (one-hour) focus groups were conducted over a 12 month period with groups of up $10-15$ students from each of the four schools. A total of 14 hours of discussions were recorded and later transcribed. They were then coded according to categories derived from the issues/topics emerging from the students' responses. The first focus group format consisted of an open discussion after students were shown a CNN video of American high school students talking about a SNS. The second focus group began with the interviewer (a member of the research team) opening with a short general 
statement about our interest in how students go about creating their profiles, establishing amd maintaining friendships, and resolving problems they might have encountered online. The interpretation of the data generated from the focus groups was further developed from observational data, and documentary data relevant to the schools. This documentary data included school policies, curriculum documents, annual school reports and so forth.

The following discussion of the data collected through the focus groups incorporates the theoretical perspectives elaborated in this paper. In analyzing students' talk, we highlight how young people (per)form co-articulation of identities and relationships across these spaces. Appadurai conceived of his five scapes in terms of "flows" to capture the idea of movement across liquid borders. We too utilize flows as a means for describing young people's movements in and through different spaces, but also as a descriptive that characterizes the spaces themselves as both fluid and flexible.

Home and family: developing a collective identity

Home is generally conceived as a private space where an individual resides in a complex figuration of kinship and belonging known as family. Home is also naturalized in a way that speaks to a universal experience. We therefore draw attention to the fact that "home" is not a stable entity, despite often being romanticized as such. As Witold Rybcznski notes, the concepts that circle notions of home such as domesticity, privacy, and comfort are achievements of modernity (1986: 7). However, when we begin to consider the ways in which home resonates with the students in the study we can see that they, like most of us, desire to belong and to be recognised as a member who belongs. More significantly for our purpose, there is a need to 
understand the way that the discourse of belonging can also encourage a sense of self as homeless. Our use of homelessness in this sense refers to how the confines and strictures of the home make way for other forms of connection that occur beyond the home. This dialectic of identity as belonging and homelessness is mediated by technology.

The home is a domestic space, but also a family oriented iScape where the reproduction of a collective identity occurs. For many young people, being-at-home connotes both structure and affiliation whereby they are afforded a sense of ownership of space and belonging, which may nevertheless be regulated by parental rules and norms. Technology often mediates this scape, extending the domestic space and family network beyond the physical limits of the home, into a discourse of belonging with a wider ethnic, religious, or kinship group. As these comments illustrate:

Female student: I need MSN so I can talk to my family who are in the Solomon Islands, because I live there myself. I live with a homestay family [in Australia], so every night I need to talk to my parents.

Male student: $\quad$ Because most of my family live in Hong Kong, like my relatives and stuff. So then if they have any particular gatherings or stuff, then sometimes we use MSN. We cam use the video conferencing thing, like the webcam thing, so you can like kind of share the moment with families.

In speaking of belonging these students also express a sense of homelessness as a feeling of displacement from family, despite living in the home of a homestay family. Thus digital media can extend the expectations of home and family as sites of nurturing and connectedness as well as 
constitute the disjuncture between "being with" and "being away from" family. Communication technologies were also reported as an inexpensive and efficient way to contact with family members who were not physically present in the home.

By bringing Appadurai's notion of "deterritorialisation" (1990: 301) to the students' experiences of being away from home (or having family who live in other countries) we can understand how deterritorialisation permits students who live away from their home and community to communicate through the use of technologically-mediated networks, which enable "home" to transcend beyond its origin place into a global space. Clearly, the impact of the Internet and global systems of communication have radically and irrevocably separated space from place, since even people in remote areas of Australia, the Solomon Islands, or elsewhere in the world communicate with family members far removed from them in space. However, acknowledging the separation of space from place does not imply that place-time relations are sundered, or that place is not resonant with significances regarding identity. Selfhood and place relate to each other, as the student from the Solomon Islands made abundantly clear - 'I need MSN'.

An integral component of the collective identity is learning to accommodate the needs of others in the family. The young people in the study were generally accepting of the needs of other family members. They articulated acceptance and understanding of others' needs as illustrated by the observation from a student: "If someone else wants to use the computer for an actual purpose you just get off." One student explained why he had to relinquish the computer at $9.30 \mathrm{pm}$, "because Mum always wants to write emails and stuff". The mother's personal time holds hierarchical sway over that of the younger family member. Another student iterated this issue of a hierarchy of needs in the home. He observed that, "because we own a business Mum is always on 
there [computer] doing bookkeeping and wages and stuff and like I used to have MSN but she had to delete it because it would slow down the Internet and she just didn't really like it". Most students reported having to share home computers with other family members such as siblings, but it was common for families to purchase an extra computer for older children who were attending university, or in the case of one student's sibling: "My sister got a scholarship so she got a laptop." This raises the question of ownership of property which is crucial to all communities and often a site of tension. In the examples offered by many of the students, ownership clearly lies with the parents, and "relations of power and discipline" (Soja 1996: 6) inscribe the domestic space and impact on the collective identity.

The boundaries of home life are established and maintained through socially constituted rules and expectations. Bourdieu's (1997) notion of "habitus" is useful for understanding how the material conditions of students' lives intersects with family social structures and modes of behaviour. Our research found that students' use of the Internet and digital technologies is controlled by family circumstances that rely on economic decisions and the values, rules, and daily rhythms of the family unit. Students reported that their use of computers is generally restricted by parental authorization. In the home, parents are the ultimate arbitrators and rule-setters. The rhythms of the household cause interruptions to online activities as one student recalled: "I'll just finish setting up ... and Mum and Dad will be like, 'Come on. Get off your laptop now. It's dinner time"”. This student was expressing his frustration with the offline demands of household hierarchies and routines that impact on his ability, as a family member, to spend uninterrupted time online. The habitus of the home incorporates a person's knowledge and understanding of the world, as well as interpersonal relations and modes of social behaviour. It also transforms the 
domestic space into an iScape as identities are negotiated in the context of co-habitation of a space that shapes and directs daily social and individual practices.

These instances of control and regulation also highlight how family hierarchies impact on the deployment of resources and rules of time management. Similar findings emerged from research undertaken by Horst and colleagues (2010). In their study of families and technology, they found that "parents sometimes assert their status in the family hierarchy by moving through the home freely, even when a space is deemed to belong to their kids" (157). The enforcement on the use of technologies in the home often comes in the form of a time limit, particularly for those students who had a generous access to them. Many students stated that during the (school) week they were allowed to go online until about $9.30 \mathrm{pm}$, but during the weekend this was extended to midnight. They were aware that their parents did not want their adolescent children to overextend the time spent online but iterated that if technologies were being utilized for education the time limits were relaxed. As Horst notes, "parents often frame their purchase of new media in relation to educational goals and broader aspirations they hold for their children" (150). In our study, students reported that parents regarded the educational use of computers as valid information gathering. From an anthropological perspective, this extends traditional nurturing and protective role of parents within the family hierarchy.

The students' reports of their participation in the flows that shape the contours and rhythms of living in the family home highlight how physical structure and identity, individual and collective, appear to be intrinsically connected. In terms of collective identities, even those students who did not live at home, there is a strong sense of identification to a familial group. In their accounts of family and family life, the students appear to think simultaneously about their identity and their 
relationship of internal cohesion and need for harmony, and thus the constituents of their shared identity as a member of a family unit. However, technology plays a crucial part in contributing to this process. Whereas the introduction of older technologies to the family home (radio, television, telephone) inevitably impacted on the internal dynamics within the home and shared collective identities by providing both communal and individual spaces for listening, viewing, and communicating, computers and the Internet have caused a further alteration to these processes. Consequently, the flows of movement, ideas, communications circulate in ways that were once not possible. For some of the parents of the students, it would seem that the change in the perception of the space-time dynamic in the home is compounded by changes in the way things were done in the past - either real or imagined. As one student said their parents did not grow up in "the massive technological era". Parents' attempts to keep the family home a closed and apprehensible space are constantly challenged by technology as it impacts on their own and their children's needs and desires. Thus, the iScape of the home extends beyond the spatial and temporal limits of its architecture, location, and internal familial jurisdictions.

\section{Technoscapes: friends, blogs, MySpace, and social identity}

The iScape that flows through and beyond the domestic space also enables young people to initiate or maintain a social identity; for some students this appears to be a more covert activity or at least one that is more likely to be under the watchful eye of parents ${ }^{\mathrm{i}}$. Students reported using technologies (MSN, Social Networking Sites, mobile phones) to connect with and extend contact with others. For many of the students, the privacy of the home provided them with the time and space to make these connections. As one boy said: "I only use MSN in the night-time, where you can't really do anything when you are at home". The relatively slower, night-time pace and 
privacy of the domestic space is a contrast to the often frenetic and crowded day-time space away from home, where the students reported that they are talking, playing sport and "mucking around". These instances confirm the view that a technologically-mediated space is productive, enabling social practices to occur both inside the home and outside its physical limits.

For the young people in our study, growing up in large cities and regional towns afforded different experiences of how the global impacts on the local and on the way they see themselves within their local environment. Several students explained how without MSN or email they would not otherwise keep "in touch" with friends who live in other countries. For others, the Internet was the means for meeting others and becoming friends: "One of my best friends, I actually met through the internet, about one and a half years ago. Then I lived in Portugal at that time and actually went to Holland and I stayed for two weeks with her. Then I met a few other people that we both knew through the internet. That was pretty cool." Students living in towns that did not have Broadband found it frustrating to use the Internet and often stated that it wasn't worth the effort or expense to their parents. Others stated a preference for "watching TV", "hopping on PS2 [playstation]", "playing with X box", "going to the park".

These comments demonstrate how Appadarui's technoscape moves fluidly and swiftly across various kinds of boundaries that were once impervious. They also demonstrate how it is experienced differently by young people. When Appadarui first developed the idea of technoscape nearly two decades ago the global configuration that existed at that time largely facilitated communication and information. The students in our study were born after the publication of "Disjuncture and Difference in the Global Cultural Economy" (1990). 
Consequently, they have only known a world where the flows, mobilities, and relations of a global cultural economy are part of the modus operandi.

For nearly all students in the study, the Internet is characterized as an efficient alternative to the school or public library: "It's good to have the Internet available. Because you're at home, you don't really want to drive to the library to get books out". Clearly, the Internet, email, and other communication technologies extend Appaduari's original notion of technoscapes which now produce different configurations for learning and sharing information, as well as for cocreating knowledge. Hughes (2004) argues that the new social contexts of online information environments constitute new types of learners and new forms of learner-teacher, and learnerknowledge interrelationships. We would add new forms of learner-learner interrelationships. Similarly, Jenkins et al. (2006: 4) suggest that students need opportunities "to develop the cultural competences and social skills needed" in these new e-technoscapes. We contend that these are also vital survival skills for full participation in iScapes as increasingly being connected or networked is important contributor to social identity. In the world that these students are growing up in, space and time are complementary coordinates that are re-defining how identity is constructed in the rapidly morphing global technoscape. Technology is as fundamental to these young people's lives, even if they prefer to 'do' other things, as it not only shapes their world, but how they live in it.

To illustrate technology's pervasive shaping influence, iScapes can operate as a cognitive construct for defining a public online identity. In order to consider how the social is involved in 
this cognitive construction, we turn now to consider the iScape through its imaginative representation that flows across the boundaries between private and public. These demarcations become more porous when young people create personal web pages or blogs, or use the Internet, bringing the global into the local. Amongst online social networks the notion of the private space is negotiated. When invited guests can gain access to personal web pages (for example, MySpace, Facebook) there is a tendency for the boundaries between public and private to become blurred. This blurring of privacy regarding SNS is becoming even more so with Google's intention to access personal data that are currently protected on certain social network sites such as MySpace. The implications of this extend well beyond a means for market surveys to issues of surveillance. In line with this phenomenon of the personal becoming public, we found that a popular site used by students in the study was MySpace, as the following comments attest: "MySpace is cool. 'Cause it's like you can design your own web page and put like what music you like on it'; and "Yeah, It's just like a personal page about yourself." This SNS offers the opportunity for adolescents to connect with others quickly and cheaply, but the degree of disclosure through the development of personal profiles was negotiable and varied. While some students expressed enthusiastic engagement with the potentialities of the site, others displayed ambivalence to the use of MySpace as a place where they wished to develop a unique identity with any significant depth. The following excerpt from the focus groups illustrate these differing perspectives:

Female 1: $\quad$ It's just like a personal page about yourself.

Male 1: $\quad$ It's a statement.

Male 2: $\quad$ Whatever makes you look good.

Male 3: It's what you really want everyone to think of you. 
Male 4: It is like your identity... It is sort of everything you think you are, I guess.

The profile pages are artifacts that support changing notions of an individual's identity. Unlike non-digital resources for marking identity, Graf et al (2008) point out that in the globalised world traditional resources for identity formation are less certain and support the notion of identity as continually constituted and distributed over different contexts. This fluidity equates with the formulation of identity, of who or what something or someone is, which ultimately relies on the dialogic of the social relationships that are enacted. Paradoxically, the uniqueness of an identity can only be negotiated within a network of relationships, and as the comments above suggest identity is how we imagine ourselves or how others imagine us.

In our study, we found that young people may be curious about web construction and wish to take on the challenge that learning a new technology can offer. Therefore it seems that doing has its own reward as the common experience of testing one's ability and learning through experience provides positive feedback without the initial intention of self-presentation. We found that some students lost interest in the site and chose not to carry out maintenance once they had mastered the skills required to build a profile. There may be collaborative creation of profiles or in some instances a friend constructed the profile page: “I didn't even make my profile, my friend did. 'Cause I had no idea how to do it. So it's basically what my friend thinks of me, not myself." The experience of this student was not unusual. For some students, siblings and friends who are familiar with digital technology would model the creation of a profile for new users with varying 
success. However, for those students who did continue to interact on the site they reported that it was important for its promise as a connecting point with others, rather than for the chance to formulate a detailed personal profile. Social network sites can be places where adolescents rehearse identities, by participating in the practices and protocols of the social space. Other people's attempts at creating profiles may serve as models for the potential formulation of an on line identity evidenced in the comment by one student that he doesn't " blog, [I] just comment on other people’s MySpace.”

One significant factor for the popularity of the site derives from the fact that "everybody" has a profile. It is considered "cool" to have a profile and "if you didn't have one you would have to be pretty popular or you would get left out". There is subtle peer pressure to conform to fashionable behaviour. Similarly, it is considered positive to have several "friends" on your profile. Friends added to the site afford a degree of status to the profiled identity: "it is just cool for someone like when you are on MSN but you get 200 friends, and you are like 'yeah'." This is considered "cool", but having too many friends can raise skepticism on the part of others. To add people you do not know is considered an act of desperation and "not cool". Thus, young people appear to be selective with whom they network, as in offline social practice although the form of technologies dictates how this can be carried out.

To this point we have considered how developing a social identity can be a productive experience whereby young people can make friends, communicate beyond temporal-spatial boundaries, collaborate on constructing profile pages, and be recognised as part of the Friends' List on a 
social network site. However, there were other times when students reported that always being available to others caused problems, especially when the students wanted to enjoy a space of their own. The idea of "being with" friends is complicated by how young people write themselves "into being" (boyd 2007:12), and by their fear of "being without" friends. Boyd argues that in choosing "Top Friends" for a MySpace profile, 'teens write their community into being; which is precisely why this feature is so loved and despised' (2007: 42). The matter of Top Friends was also identified by students in the study as being a point of contention:

Male : $\quad$ Yeah. Top Friends. People really get cut up there. They'll be like "Why am I not your top friend?’. Or they keep on talking, just so they can get in that hierarchy chart.

Female: $\quad$ There was a fight with two girls in my grade because one girl wasn't in the other girl's MSN name. So they were like screaming at each other. They were like "I hate you" down the hall and stuff.

These accounts given by the students in the study suggest that "being there" in terms of a Top Friends list or a MSN address book is a high priority for some young people, and not being included on a Top Friends list or on a MSN list of friends can have negative consequences, which impact on relationships and a sense of belonging (or not) to a particular group of computermediated friends or groups. We can theorise this shifting nature of identification by drawing on Gell's (1998) discussion of the variable agencies of those involved in relationships surrounding the creation of art objects. Drawing on the notion of fractal or distributed identities, Gell notes that as art objects and people move through socially constituted relationships, there is a shift in 
the exertion of meanings and power attached to the objects and to those who are connected with them. Therefore, the Friends' List is a similar artifact or object that is subject to change yet is perceived as carrying considerable meaning and power in terms of an individual's value. As the comments demonstrate, the effect on an individual's sense of identity and worth can be significant.

A social identity mediated by technology brings a form of surveillance that extends beyond the family. Albrechtslund (2008) argues that the surveillance practices that operate in social network sites challenge traditional Foucauldian notions of surveillance as mechanisms of control and disempowerment by offering more positive outcomes. By adopting the notion of "participatory surveillance", Albrechtslund argues that this more positive interpretation becomes a "way of maintaining friendships by checking up on information other people share". For Albrechtslund, "checking up" on your friends is a pragmatic issue as online technology has increased the number of friends through its global reach. The corollary is that you might also want to be the one whose friends are checking up on. One of the male students in the study clearly liked the idea that someone might be "checking up" on him, for it meant his friends were interested in him: "Say you're away for like the weekend down the coast. Oh, I can't wait to go check my MySpace and you've got like new picture comments, new messages, new comments, new friend requests, new birthdays and all that. You're like oh YES!". Other students also reported that much of their time online was spent checking up on other people's MySpace pages as the following exchange highlights:

Female 1: $\quad$ You can look at other people's MySpaces and go through everything. 
Male 1: $\quad$ Yeah, I do that.

Male 2: $\quad$ Everyone should do that.

Female 2: $\quad$ That usually takes up most of the time.

Participatory surveillance, however, may also bring unwanted intrusion and a set of unwanted expectations regarding another's availability, a point several students in the study raised, especially with the use of cellphone texting and MSN. Furthermore, keeping in touch with friends online becomes a daunting task that exceeds the normal constraints operating in offline contexts. The following comments from the students capture these negative aspects:

Female 1: $\quad$ I end up just replying to people who have texted to me. Then it just keeps going on, because they'll text back to me. I may not want to reply to it but then they'll get mad at me for not replying.

Male 1: $\quad$ It can be annoying sometimes.

Male 2: Just say you're out of credit or something like that.

Female 2: $\quad$ Like I'm on MSN and someone keeps talking to me. They won't leave me alone. So I'm like, “I've got to go out to dinner or whatever.” Then when I go out, they keep texting me and they won't leave me alone. So I'm like just leave me alone.

Male 3: $\quad$ Probably the innovation with MSN is being able to change your status. Because it just... I'm busy. So therefore you can kind of ignore someone, but, like, you're un-busy. 
These responses demonstrate the relationship between self and others as part of young people's social identity construction. However, the examples also highlight the difficulties of round the clock digital access with peers and other networks that exacerbate tensions between public identity and sociality and the need for privacy and the construction of the self as an individual.

\section{Conclusion}

This paper has attempted to draw out and elucidate some of the contextual issues that digital technologies present to young people, their families and friends. In exploring the questions we posed at the outset - "How do interactions across iScapes impact upon the identity work carried out by today's youth?" and "How do young people negotiate the diverse, physically located, social situations that arise from these interactions?' - we have drawn on relational theories of space-time, and youth identity construction to enable us to read and interpret the findings of our study. We have also attempted to build on current research on youth identity in online environments by utilizing iScapes as a conceptual tool. We have argued that while iScapes owes a debt to Appadurai's coining of scapes, it nevertheless provides a more glocalized and appropriate way for conceiving the global - local flows that move through the everyday lives of young people, and takes into account both the individualizing aspects of new technologies, identity construction and charting life-biographies, as well as the collective imagining made possible by the rapid flows of ideas, images, sounds and so forth through these socially constructed iSpaces. As a conceptual tool it has limits in terms of what it can and cannot do. Its usefulness lies in its contemporaneity as a neologism that captures how identity is enmeshed in a technological landscape of information, Internet, and interconnectivity. Of course, the risk is that 
it is dismissed as just hype, part of a passing fad of technological neologisms. Our counter is that new words are always being coined to describe new things, and are useful, if even only for a short period, to express the moment. Just as the suffix "scape" has demonstrated the way that more familiar words can take on a new meaning, so too we offer another small morpheme ("i") as an example of how we can attempt to reconceptualise and redescribe the familiar in new ways.

Technological innovations have a number of liberatory qualities, the most obvious being the reduction of cost and time of movement over space, but like their offline counterparts digital environments are also characterized by regulatory practices and protocols. In this paper we have employed the notion of iScapes to examine online and offline spaces with a particular focus on the ways in which Australian youth use digital technologies to build, extend and maintain personal networks and negotiate appropriate collective and personal identities. Through the mediation of digital technologies the social networks of contemporary Australian youth are not singularly moored to a static and localized community, but flow across iScapes that comprise diverse others. We have found that adolescents' contemporary social networks are not necessarily far-flung or fragmented but their relations in cyberspace prove to be an additional dimension to the already socialized scapes of community networks. Focusing on such locally distributed identities, formulated in personal family, peer and school-based networks has given us a particular perspective requiring attention to technologically-mediated spaces.

Young people not only occupy both "virtual" and "real" spaces simultaneously, but live and imagine themselves and others in these spaces. In our view identities are formed through an interpenetration of practices across and within inhabited and imagined iScapes. Our approach has 
allowed us to view the importance of the relation between online/offline contexts and thus concentrate on how relationship and identity work is carried out in diverse environments that are mediated by and through technology. This process is dialogic and grounded as subjects move across porous borders of their own making. In everyday iScapes, regulated and constrained by context, the advent of digital technologies have further complicated the interpenetration of the social construction of space. Today youth operate within and across these multiple and simultaneous space-time contexts to demonstrate and build identities and social competency.

Note

${ }^{1}$ Recent developments in Spyware is being promoted to parents in Australia as a way of keeping track on their children's use of mobile technologies. Parents can check up on text messages received and sent by their children. See: http://www.mymobilewatchdog.com/ 
References Cited

Albrechtslund, Anders

2008 Online social networking as participatory surveillance.

[electronicversion] Firstmonday.13(1)

http://www.uic.edu/htbin/cgiwrap/bin/ojs/index.php/fm/article/view/2142/1949.

Accessed 16/11/08.

Appadurai, Arjun

1996 Modernity at Large: Cultural Dimensions of Globalization. Vol 1.

Minneapolis: University of Minnesota Press.

Appadurai, Arjun

1990 Disjuncture and difference in the global cultural economy. Theory, culture and society. $7(2-3): 295-310$.

boyd, Danah

2007 Why youth (heart) social network sites: The role of networked publics in teenage social life MacArthur Foundation Series on Digital Learning - Youth, identity, and digital media Volume, at http://www.danah.org/papers/WhyYouthHeart.pdf. accessed 11 November 2008.

Buckingham, David

2008 Introducing identity. In Youth identity and digital media. David Buckingham, ed. Cambridge, Massachusetts: MIT Press

Castells, Manuel 
2001 The internet galaxy: reflections on the internet, business, and society. Oxford: Oxford University Press.

Dodge, Martin \& Kitchin, Rob

2001 Mapping cyberspace. New York: Routledge.

Gell, Alfred

1998 Art and Agency: an anthropological theory. Oxford: Oxford University Press. Graf, S. C. Mullis, Ronald L. Mullis, A. K.

2008 Identity formation of United States American and Asian Indian Adolescents. Adolescence 43(169): 57-69.

Harvey, David

1990 The Condition of Postmodernity. Malden, Mass: Blackwell.

Heyman, Josiah, McC., and Campbell, Howard

2009 The anthropology of global flows: a critical reading of Appadurai's "Disjuncture and difference in the global cultural economy". Anthropological Theory 9(2): 131148.

Horst, Heather

2010 Families. In Hanging Out, Messing Around, and Geeking Out: Kids Living and Learning with New Media. Mizuko Ito et al. Cambridge: MIT, 149-194.

Hughes, Christina

2004 New times? New learners? New voices? Towards a contemporary social theory of learning. British Journal of Sociology of Education, 25(3), 395-408.

Jenkins, Henry, Clinton, K., Purushotma, R., Robinson, A. J., \& Weigel, M.

2006 Confronting the challenges of participatory culture: media education for the $21 \mathrm{st}$ century. Chicago: MacArthur Foundation. 
Leander, Kevin and McKim, Kelly

2003 Tracing the everyday 'sitings' of adolescents on the internet: a strategic adaptation of ethnography across online and offline spaces. Education, Communication and Information 3(2): 211-240.

Lefebvre, Henri

1991 The production of space. Cambridge MA: Blackwell.

Lewis, Cynthia \& Fabos, Bettina

2005 Instant messaging, literacies and social identities. Reading Research Quarterly 40(4): 470-501.

Livingstone, Sonia

2009 Taking risky opportunities in youthful content creation: teenagers' use of social networking sites for intimacy, privacy and self-expression. New Media \& Society 10(3): 393-411.

Robertson, Roland

1995 Glocalization. In Global Modernities. Mike Featherstone, Scott Lash and Roland Robertson (eds). London and Thousand Oaks: Sage, 23-44.

Rybcznski, Witold

1986 Home: A short history of an idea. New York: Penguin.

Slater, Don

2002 Social relationships and identity online and offline. I $n$ Handbook of new media: social shaping and consequences of ICTs. L. Lievrouw and Sonia Livingstone, eds. London: Sage.

Soja, Edward W. 
1996 Third space: journeys to Los Angeles and other real-and-imagined places.

Malden, MA: Blackwell.

Twenge, Jean M.

2006 Generation me. New York: Free Press.

Valentine, Gill and Holloway, Sarah

2002 Cyberkids? Exploring children's identities and social networks in on-line and offline worlds. Annals of the Association of American Geographers, 92(2):302-319.

Wegner, Phillip E.

2002 Imaginary communities. Berkeley: University of California Press.

\footnotetext{
${ }^{\mathrm{i}}$ Recent developments in Spyware is being promoted to parents as a way of keeping track on their children's use of mobile technologies. Parents can check up on text messages received and sent by their children. See: http://www.mymobilewatchdog.com/
} 